\title{
Copying, copyright and originality: imitation, transformation and popular musicians
}

\section{Keith Negus}

Goldsmiths, University of London

John Street

University of East Anglia

\section{Adam Behr}

Newcastle University

Abstract

With copyright becoming ever more important for business and government, this article argues for a more nuanced understanding of the practices and values associated with copying in popular music culture and advocates a more critical approach to notions of originality. Drawing from interviews with working musicians this article challenges the approaches to copying and popular music that pitch corporate notions of piracy against creative sharing by citizens. It explores differing approaches to the circulation of recordings and identifies three distinct types of creative copying: i) learning through imitation, ii) copying as transformation, iii) copying for commercial opportunity. The article then considers how copying is caught between a commercial necessity for familiar musical products that must conform to existing expectations and a copyright legislative rationale requiring original sounds with individual owners. The article highlights how legacies from a long history of human copying as a means of acquiring knowledge and skills leads to a collision of creative musical practices, commercial imperatives and copyright regulation and results in a series of unavoidable tensions around originality and copying that are a central characteristic of cultural production.

Keywords: musicians, copying, copyright, recording industry, originality.

Copying has been an enduring feature of music making in two interrelated ways. First, copying as transcription of compositions or performances, and as phonographic reproduction, has been central to the communication and circulation of songs, instrumentals and ideas. Second, copying 
from existing songs, performances and instrumentals has been an important part of the creative process, as musicians have sought inspiration and signalled their membership of genres and located their style within traditions. The two practices are connected because circulated music (whether recordings or printed pages) has provided an impetus for the acquisition of musical skills, exchange of ideas and accumulation of knowledge.

Yet, copying has increasingly been perceived as a problem by music industry trade organisations seeking to profit from selling commodities to consumers, whilst maintaining a legal regulatory framework premised on intellectual property. In this paper we explore the tensions as popular music practice collides with competing artistic impulses, commercial incentives and legal imperatives. We draw from interviews with professional UK based musicians working mainly within and across rock, jazz and sample based genres, and those who work with and represent musicians, in order to open up discussion about broad similarities regardless of differences of genre and cultural identity. ${ }^{1}$

The quotations and paraphrased issues in this paper are drawn from in-depth interviews with 21 full time working musicians (some also gaining income from giving instrumental tuition), aged between their early 20 s and early 60 s. We selectively approached musicians with sustained careers of releasing recordings and performing and with some degree of experience of practices relating to copying and copyright. The aim of this study was very much to explore issues in depth through qualitative research, asking musicians to articulate and to reflect upon matters that they rarely address overtly in their practice. Whilst keen to hear from practitioners working across different genres within popular music, as broadly understood, and to get a sense of how attitudes and practices may have changed over time, we did not seek a 'representative sample' of anything (aware also of the practical and philosophical problems of making any claims about any 'sample'). We did not ask musicians how they defined their class, racial or sexual identities and these social attributes did not arise as a significant issue for copying during our interviews. Only two of these musicians were women, and we acknowledge that further research may explore the extent to which male and female musicians may adopt different approaches to copying. We also interviewed two artist managers with some 20 years experience of managing bands, an expert witness with experience of advising in copyright infringement cases and four personnel working for music industry trade organisations. Interviews were conducted between October 2013 and January 2015. For logistical reasons the interviews were conducted in London, Edinburgh and 
Glasgow. Interviews were conducted on the agreement of anonymity to encourage respondents to be open about their practices and to maintain confidentiality. We have also draw widely on published interviews with musicians and a range of secondary sources in which these issues are debated.

We focus on musicians in contrast to the tendency of recent writings to present arguments from the perspective of an industry and its elite of successful artists or a multitude of creative users. We seek to challenge the way discussion often veers in two incompatible directions, one towards 'theft' or 'stealing' the other towards 'borrowing' or 'sharing'. Focusing on the experiences and beliefs of musicians allows us to explore the practical and ethical decisions and dilemmas that are often unacknowledged with the collapsing of distinctions between a relatively straightforward act of reproducing and passing on or allowing access to a digital file, and a more multifaceted creative practice entailing use of and reference to existing work. As the argument about piracy and stealing is primarily posed by the recorded music industry and sharing embraced by theorists of active and creative citizens, the experiences of practising musicians leads us to a series of more nuanced relationships between notions of copying, creativity and originality.

We address arguments for the positive value of copying in two senses: First, the important cultural, educational and creative role of circulating recordings outside of any direct payment made by consumers or revenue being received by musicians. Second, the importance of copying as an impetus for the acquisition of skill, innovation and, not least, as a stimulus for achieving the commercial goal of making profits.

We first acknowledge contrasting generational and changing historical responses to digital circulation. We then identify three broad ways that copying informs the creative practices of musicians. The first of these is a more informal process of learning by imitation, a practice that has a long history in music pedagogy and endures on instruction videos made and uploaded to YouTube. Second, is copying as revival, remodelling and rewriting - an activity characteristic of many art forms that seek inspiration from the past. Third, we identify a more calculated act of copying for commercial gain entailing covers or sound-alikes. It is in this area where accusations of plagiarism are most often negotiated, and we highlight how this occurs according to ethical ideas about artistic respect and responsibility. A key theme we wish to stress throughout this article concerns the way legacies inherited from a long history of vernacular and formalised human 
learning and creation is in conflict with music as original copyrighted commodity with identifiable owner as originator.

Although the main sections of this article focus on copying in creative practice, the circulated recording weaves throughout and is central to how skills are developed, allegiances communicated and creative ideas expressed. For a recorded music sector, the circulation of recordings may have been primarily about making profits from the sale of individual products, but for many musicians it has been central to learning, copying and creating. Whilst sharing on the internet has allowed musicians to learn from notation of various kinds and transcribed lyrics, the recording continues as the main currency through which musical ideas are exchanged, circulated and appreciated regardless of its value as an artefact for listeners or the price it might fetch for labels competing in the marketplace.

\section{Copying and digital circulation; resistance, adaption, acceptance}

Since the turn of the new millennium copying has preoccupied those sectors of the music business anxious about a decline in revenues from the sales of recordings to consumers and trying to comprehend how digitalisation has changed the habits and values of listeners (Hardy, 2012; Leyshon, 2014). Reports published by the International Federation of the Phonographic Industry have regularly emphasised unregulated 'pirate' copying, illegal circulation and peer-to-peer sharing when accounting for loss of revenues (see IFPI 2011, 2012, 2013, 2014). This has resulted in the 'criminalisation of sharing' (David, 2010) and prosecutions of individual consumers for downloading tracks accessed from other fans (Alderman, 2002; Knopper, 2009), along with prosecutions of organised criminal entrepreneurs, such as Kim Dotcom, for profiteering by encouraging music circulation without rights payment (Forde, 2012). Research by academics has consistently contradicted the recording industry's straightforward causal claims about the impact of illegal downloads and peer-to-peer sharing, suggesting that this has had a negligible impact on sales revenue and is indicative of a change in the way consumers wish to engage with music rather than simply the result of piracy (Aguiar \& Martens, 2013; Rogers, 2013). As the founders of Spotify recognised, peer-to-peer circulation produced a space for those who wished to listen but who do not want to purchase, prefiguring access to streamed music (Milne, 2014). 
A considerable body of research within media and cultural studies has sought to emphasise the broader value of unrestricted copying by showing how this has allowed consumers to realise themselves as creators and participating citizens over a longer historical period than that during which digital 'piracy' has been viewed as a problem (see Lessig, 2005; Johns, 2010). Our specific focus on musical copying in this article could be viewed as one aspect of a broader and more profound practice of 'commons-based peer production' (Benkler, 2006). The value of copying in popular music culture has been a salient theme in writings on remixes and mash ups (Lessig, 2008; Shiga, 2007; Brøvig-Hanssen \& Harkins, 2012) and in those writings that offer both a philosophical and policy aware counter argument against the corporate demonization of piracy (see McLeod \& Kuenzul (eds) 2011; McLeod \& DiCola, 2011). We take inspiration from the way this body of research has argued for the importance of copying and how it has facilitated aesthetic change, bonds of social communication and individual creative fulfilment (enabling users of media and art forms to become creators). However, research on copying in popular music culture tends to draw from theories of how active audiences and citizens are able to positively redefine media products and culture forms. We wish to add a further dimension to studies that value copying by focusing on these issues from the perspectives of production (rather than use) and from the viewpoints and practices of working musicians. Whilst we certainly wish to draw attention to the positive value of copying, we also want to address the ethical dilemmas and ambiguities experienced by musicians. We will be highlighting and exploring, tensions between principles and beliefs that may come under question and which can be challenged during songwriting, composing and recording. Our research initially suggested varied responses amongst musicians in relation to questions about the loss of income from recordings.

The economic impact of illegal sharing and downloading continues to be accepted as a major concern by musicians who established their careers with regular income from recordings rather than from touring, session work and live shows. The belief that fans circulating and sharing tracks is depriving musicians of a livelihood by stealing was famously expressed when the rock band Metallica sued the peer to peer platform Napster, identifying digital music 'piracy ... as ... trafficking in stolen goods', a theme that became repeated in the many claims made by the recording industry and artists of this generation (see Alderman, 2002; Marshall, 2002). Yet, the target of anger has noticeably shifted with growing awareness that profits are being generated by phone and computer companies using recorded music as a 'customer engagement tool' (Seabrook, 2014), leading to renewed claims of an inequitable allocation of this revenue to 
musicians and between the different industries with a stake in recorded music (see Negus, 2015). Whether the villain is the fan in their bedroom downloading shared files or the data and phone companies not passing on a fair share of revenue, many of these musicians cling to the idea of recordings as an artefact that should be paid for by consumers.

However, some musicians have modified their attitudes over time and have reached a similar belief to that of younger musicians who have come to accept that a digital recording is something that is offered for little financial return on its own terms. In the period of time since digital recording was introduced the economic value of live shows and touring has increased dramatically (Behr, Brennan, \& Cloonan, 2016). Whilst still believing that they should receive income from recordings, older musicians we spoke with have pragmatically come to recognise that a recording has become more significant for how recognition is accorded and to the way money is made from performances and merchandise, or from session work (gigs gained as a result of circulated recording). A member of an acclaimed band, who is also an experienced producer, explained how he had reluctantly come to accept the situation:

It's a promotional tool. ... Music's been devalued and so, to get people to hear it, you have to give them a free sample ... I've never felt comfortable with it because I'm a bit old school in the sense that I feel like, "You've worked hard and people should pay for it". But the whole industry, since Napster basically started the free sharing thing, however long ago it was, that literally changed the whole game.

For younger musicians with no experience of income from sales of recordings the issues are more straightforward. An electronic, sample based musician, spoke of how he had grown up not expecting to make money from recordings:

I've never really received much in terms of income from recorded music and selling my recordings or recordings of my music either through the band or on my own. For that reason it's not a concern. If I were to make the majority of my income from selling my records, it would be more of a concern. But because I make the majority of my income from live performances and things like that it's not really something I think about too much. ... 
A guitarist member of a band who release recordings using creative commons licenses thought that fans sharing recordings was not an issue because 'for the vast majority of bands the challenge is not, "I must protect my stuff", it's "How do I get heard?"'. This musician also stressed that this was also a business decision 'because the route to fandom is recommendation, listen, love, buy'.

Our interviews were conducted when subscriptions to streaming services (such as Spotify, Deezer, Apple Music) were increasing and illegal downloading declining, partly due to the success of industry organisations in lobbying to block sites, and also due to listeners preferring streamed content over downloads, whether paid for or not (see Marshall, 2015; Morris \& Powers, 2015). Recent anxieties about digital copying are but the latest episode in a longer running tale of 'illegal' reproduction of recordings (Cummings, 2013), and echo the paradoxes of the 1970s when Philips manufactured tape machines that permitted consumers to copy onto portable cassettes whilst their music division, PolyGram, was a member of the British Phonographic Industry (BPI) campaigning with the slogan 'home taping is killing music' (Cummings, 2013). More enduring has been copying in the creative process, the issue we now address.

\section{Creative Copying 1: Learning through intuitive, informal and institutional imitation}

Copying as a way of gaining understanding and learning to do something is possibly an innate human impulse, and how we achieve such basics as walking and eating. As Lucy Green has observed in her studies of how children learn to become musicians: 'Children not only copy the behaviour of adults and other children, but they also make copies of objects which they find in the environment' (Green, 2002: 60). Green has also highlighted how 'learning by listening and copying... combined with close watching, has always been the main means of learning in all folk and traditional musics and many art musics undoubtedly since the dawn of humanity' (Green, 2002: 186).

Pete Seeger, one of the most influential twentieth century archivists, composers and activists, a musician who played an important role in protest and the civil rights movement, once explained folk music as 'not any particular song, it's not any particular singer. It's a process by which ordinary people take over old songs and make them their own' (Zollo, 2003: 5). Ordinary people taking over songs and making them their own might apply to any musicians, DJs, songwriters and producers 
working in any contemporary genre of music as much as it describes the way children intuitively acquire musical skills, as Green found in her research.

A commercially successful songwriter was asked to reflect on how he balances influences and originality when composing. His seemingly jumpy and hesitant response, as transcribed, is indicative of how these issues are not easy to articulate and resolve:

The other day, for example, I was studying how the chord progression in 'Starman' by David Bowie went because that was the sort of thing. And we didn't do the same thing but by analysing it you can work out how the lift works, coming into the chorus, and where the minors go, which leads into the, um... But these are kind of technicalities which aren't really... I don't think that it's... It's copying but it's not plagiarism as such. Music is, music has always been a progression about people learning from each other.

Although he was asked about influences and originality his response directly led to the issue of learning by instinctively analysing and imitating structures, patterns and sequences. Musicians also copy from recordings when acquiring the skills to achieve sonic qualities and the timbres of performance, a point also emphasised by Green:

By far the overriding learning practice for the beginner popular musician ... is to copy recordings by ear ... It seems an extraordinary fact that many thousands of young musicians across the world have adopted this approach to learning over a relatively short space of time - covering a maximum of eighty years since sound recording and reproduction technology began to be widespread - outside of formal networks, usually at early stages of learning, in isolation from each other, without adult guidance and with very little explicit recognition of the ubiquity of the practice across the world (Green, 2002: 60-61)

Numerous musicians across genres have spoken of how they learnt their craft and developed their initial attempts at songwriting, performing, making beats or developing rhymes from these two inter-related types of copying - analysing the structural components of songs and listening to recordings (see Zollo, 2003; Cross, 1994). 
Learning through imitation has been formalised as a pedagogic practice as evidenced in instruction manuals, instrumental tuition (mentioned by a number of our interviewees) and notable in a plethora of online videos in which professional teachers or enthusiastic amateurs seek to pass on their knowledge.. An experienced drummer who also teaches commented:

Imitation is the sincerest form of flattery. I mean, that's where your influences come from. And that's what I teach, as well, I say, "Get your favourite musicians: copy them. Why not? That's OK". You're never going to do it exactly, exactly: no one can play the drums like Stevie Wonder or play the drums like Steve Gadd. You just get the essence of it.

This is copying as part of a tradition going back at least to the Italian Renaissance when imitation was central to learning. Howard Mayer Brown writes of 'what must have been one of the most widespread practices in all branches of artistic endeavour in earlier, as indeed in modern, times. Composers as well as poets and painters learned their craft by imitating older masters. Composers modelled new pieces directly on old ones' (Brown, 1982: 8).

Popular musicians who learn by copying from audio and visual recordings, and who teach the art of copying as a way of achieving skill and understanding, are participants in a long history that travels through key moments in canonical European art, poetry and literature, and threads though countless folk, blues and vernacular traditions, enduring in school classrooms where children are encouraged to work out how to perform popular songs by imitation (Green, 2008). Its legacies are on YouTube where imitation is advocated as a way of learning a guitar or trumpet solo, an instrumentalist's timbre and for appreciating the art of particular musicians.

\section{Creative copying 2: Transformation through rewriting, remodelling and revival}

Whilst learning and accumulating knowledge through imitation may lead to adroit replication and accomplished impersonation, the possibility of transformation is also inherent in learning by imitation as Peter Burke noted in his introduction to the Italian Renaissance that 'imitation was not slavish ... The aim was rather to assimilate the model, to make it one's own, and even, if possible, to emulate or surpass it' (1997: 17). The importance of imitation has been identified as a more general cultural dynamic and evoked to explain how Japanese musicians have copied African-American performers by adopting black face. Shuhei Hosokawa has argued that 'mimicry is 
a key process by which a cultural form is transferred from one place and person to another, and by which the boundaries between the original and the copy, the desired object and the mimicking subject, are blurred ... The term influence always connotes a certain degree of imitation and mimicry' (2002: 223/4).

Imitation, mimicry and referencing is crucial to how musicians communicate their ideas, compete and collaborate, and central to a creative process whereby existing musical ideas are transformed into new music. Influence is used to signal affiliation and as a way of creating new music as conveyed in the following comments from a musician with considerable experience of producing and performing jazz, Latin and funk:

We would absolutely be saying, "That snare sounds like the Ohio Players from 'Fire'. That's great. That's what we want a snare to sound like. Right, keep that snare. That's brilliant". So we would absolutely be thinking "Can you not get the bass to sound exactly like the Gap Band [sings bass sound]. Good, we got it." So on the technical level we would absolutely be completely, I don't know, copying, imitating. But mixing them through, with a few different things. Again, it was our own thing. So we never felt any shame about that.

A number of our interviewees spoke of seeking ideas by looking back to a particular period either immersing themselves in a genre or style in an attempt to absorb and to imitate its key qualities and characteristics or replicating and learning from individual songs. So, for example, one member of a 1980s rock band explained how one of his critically acclaimed songs was modelled on Syd Barrett's 'Octopus'. He had 'obsessively' listened to Barrett's song 'over and over again', worked out the structure, written out the lyrics and used it as a model. He was asked if he could remember his attitude to copying at the time and responded that he was not bothered 'because that's what songwriters do anyway'.

Jazz musicians provide a bridge linking the highly trained notational literature musician and the autodidact with keen ears. One we interviewed discussed the simultaneous imitation, homage and inspiration that can form the basis for transformative composition:

The trombone player brought in a set of changes he thought were great, but it turned out was a Steely Dan song probably, you know, really close to a Steely Dan song. But we used it anyway 
and had a laugh because we were with $\mathrm{X}$ [name removed] at the time and we just though it was a bit of fun. So homage would often happen.

A member of a band that had a number of hit singles in the UK in the 1970s recalled looking back and seeking inspiration in styles from the 1940s to the 1960s:

Well, you know, I make no secret of it, we were such huge fans of that kind of era of music Doowop, R\&B, through to soul, black music basically from sort of ' 40 s through to the ' 70 s, that in terms of our writing we purposefully wrote and came up with arrangements that mimicked those records that we loved. And, yeah, we made no secret of that and we never ever were challenged about it. You know, '[song titled removed]' and '[song title removed]' that I wrote are very, very ... they draw very, very heavily on well known soul and Motown tracks. It's just something you did.

Simon Reynolds has been dismissive of those who look to styles from the 'immediate past' and within 'living memory', arguing that a conservative backward looking 'retromania' has become dominant, a practice that can be distinguished from the 'antiquarianism or history' of the Renaissance, gothic and folk revivals (Reynolds, 2013: xiii-xiv). But Reynolds evades the important ways that twentieth century mass mediated and twenty first century digitally circulated popular culture has been a significant 'immediate past' and provided a stimulating repository of repertoire for inspiration, learning, homage and renewal.

The folk revival movement, for example, acquired momentum as a response to industrialisation, urbanisation and the impersonal institutions of modernity. The revivals of the nineteenth and early twentieth century elevated rural themes as part of a pastoral critique of modernity whilst the revival of the late 1950s which led directly to the protest music of the 1960s, sought inspiration in the values of a radical 'people's' music, celebrating strands of urban resistance to capitalism and industrialisation as a way of renewing a sense of commitment to social causes and to evoke a new music community at odds with 'mass culture' (Brocken, 2003; Lloyd, 1967). Like the nineteenth century Gothic revival, and the ways of making things associated with William Morris and the arts and crafts movement, the folk revival sought inspiration in a set of aesthetic and human values, sensibilities believed to have been lost with the rise of consumer culture and advertising (see Williams, 1963). 
Our point here is that revival is thus not simply about seeking re-birth by borrowing a style from the past but entails an ethical and moral commitment connecting musical practices to structures of feeling and sentiments. Revivals are not just about a style, but also an attempt to retrieve and retain a set of ethical and artistic values.

\section{Creative copying 3: Covers, clones and commissions}

Cover versions, tribute bands and the performance of 'classic repertoire' has been a characteristic of post-Second World War popular music culture, impulses driven by the desire to use familiar sounds to reach a recognisable commercial market. Musicians avoid or abandon any opportunities to be original or innovative, using imitation to copy for commercial ends rather than as a means of learning and acquiring knowledge. As Andy Bennett has written

One of the defining characteristics of popular music performance since the rock' $n$ 'roll explosion of the mid-1950s has been 'imitation'. Throughout ensuing decades, the hits of the day have been slavishly reproduced or 'covered' by local bar and pub bands in cities and towns throughout the world. In more recent years, this desire to imitate has taken on a significant new dimension in the form of the tribute band. (2006: 19)

Many musicians have found that they have been unable to earn a living performing their own unknown material and have taken the tribute band option as a way of making a regular income, sometimes using this to finance other more personal projects.

As well as a straightforward commercial decision, there is a certain postmodern irony at play in the way that the copying of tribute acts and cover bands is judged. The tribute act avoids accusations of insincerity and pejorative dismissal as derivative, maintaining its integrity because it cannot be accused of presenting an impersonation as original.

This is not the case for composers who earn a living from commissions stipulating the production of sound-alike work - a composition that is entirely derivative of an existing piece of music. Such work is contracted because a musician or band has refused to license or to allow a recording or song to be used in an advert, or because an agency does not have the budget to pay for the 
original and requires a sound-alike. One musician recalled how he was asked to follow a very specific existing work, and after considerable endeavour was told that his work was too close to the original to be used. Yet, a representative from a trade organisation with considerable experience of working with songwriters and composers thought that it was far more common for media composers to have their work rejected because it was just not close enough to the piece they were required to copy.

An instrumentalist, composer, producer and teacher spoke of these dilemmas when asked whether he worried about copyright when producing sound-alikes:

Well, I worry about it when there is an actual verbatim repetition of a chunk of a melody, for the simple reason that most of the time we are already - when we do sound-alikes, we are doing stuff that we are deliberately sounding like an original track. So, at that point, you have to be very aware of what you're doing. If then you suddenly start coming up with snippets of melody - it's easy to do, because everybody has got the original in their head - then you're asking for it. ... the secret, I think, for successful sound-alikes, is to do something that's inspired by the original, but it has an essence of originality about it, too. So, if somebody said, "Let's just blatantly copy Stevie Wonder," it would sound like a blatant copy of Stevie Wonder: it doesn't really have that original essence. Whereas if you say, "Look, I want a funk thing, Motown style, really soulful, busy, plenty of clavinet, slightly sloppy, funky drums" - Stevie style, but what have you got? Someone will come up, there are oodles of artists who've done that, and they can do it quite successfully, some of them.

Despite this composer's avowed intent of seeking an element of originality when making a soundalike, it is usual for the commissioning company to request a copy of an identifiable composition. The inclusion of original elements may lead to rejection and wasted time composing and recording. As the same musician also acknowledged:

When I'm doing advertising, stuff like that, you know sometimes we do adverts, and we think, "Oh, that's very, very close, I mean, they obviously know what they're doing before they put that on TV, but to do stuff like that" - they know, they've got to make a decision. People do get sued: they do get sued. ... in general, people know, when they go for stuff, they know roughly 
what the law is. ... You know how far people stand away from the bonfire in order not to get burnt, and that's how it's policed.

The issue of sound-alikes draws attention to some of the ethical dilemmas in copying. The musician quoted above retained his sense of integrity through the belief that he was putting something 'original' into the composition. Yet he was acutely aware that the production of a sound-alike pushes right up to the limit of plagiarism. Sound-alike composition is premised on a deliberate imitation of an existing recording for quite calculated commercial reasons - usually this is for an agency wishing to use the track to create brand identification with sounds that signify a historical period or lifestyle with the aim of increasing sales and psychological affiliation to products. It is here - in both creating and responding to sound-likes - that copying accrues ambiguities and poses ethical dilemmas, an issue we pursue in the next section.

\section{The ethical aesthetics of copying}

Both sound-alike composers and commissioning companies are aware of legal disputes about plagiarism. The convoluted history of music copyright is usually traced to 1777 when Johann Christian Bach and Carl Friedrich Abel claimed against publishers Longman and Lukey for reproducing and selling unauthorised copies of compositions. Although the issue concerned circulation, as Arewa Olufunmilayo points out 'with the application of copyright to music came greater awareness among composers that their work constituted intellectual property that had economic value' (2011: 1838). Yet, this awareness initially only influenced copying in circulation and not copying as part of the creative process, the latter gradually become an issue throughout the nineteenth century, as Donald Burrows (2012) has written in his account of Handel's use of other composer's material, and as Ronald Rosen (2008) has observed when comparing Concertos composed by Vivaldi in 1712 and J S Bach in 1730. Copying and reuse was as much part of an art music tradition as it is integral to various forms of folk and vernacular music making.

Plagiarism can be intentional, as in the case of sound-alikes and in Handel's borrowings. Or it can be unintentional. The line between being influenced and cryptomnesia was articulated in this quote from a musician who made a living from composing, producing and performing alternative and electronic music: 
I'm sure I remember bits where I'd written a part over something and then someone's had to go, "No, no, that is the riff from someone else's song". You go, "Oh, shit, it is". And that's happened, and it's not been, of course, intentional, and you've just sort of worked something out and it sounds right, and then you realise that you're just replaying something. I think in hindsight you go, "Oh, yeah, there are bits in those songs where I know exactly what I was listening to when I wrote it". And I can pretty honestly say that I don't think any of it was intentional. And I can pretty honestly say I don't think, at the time, I perhaps realised how close it was.

It is here where imitation as creative practice can clash with ethical principles that are articulated in relation to copying. The musician cited above is not alone in having unintentionally copied, nor in looking back at past work and retrospectively realising just how close his music was to that of other composers. One manager with nearly 15 years experience of representing musicians referred to how an act had been approximated by a sound-alike in these terms: 'It sounds like a re-recording of the track, and they've just taken some of the lyrics and the key things, so it's quite a brutalisation of the track itself, which in itself is nasty, not a great thing to hear.'

Here copying is mediated by beliefs about compositional integrity and authorial responsibility towards other songwriters and performers. As one musician commented:

I think there's a respect agenda, and always the top musicians are not going to want to be seen ... as someone who nicks other people's tunes, for want of a better expression! The plagiarist is an interesting example, because it's a terrible thing, it's a real insult to the person it's aimed at, and everybody knows the story, and you would hate someone to even consider doing that to you.

Not only is there a 'respect agenda' among musicians, the internet and digital circulation of music via various discussion pages, blogs and forums has alerted musicians to how listener discussions are informed by an ethics of copying and influence. As the manager cited observed: 'I think as soon as you get a group of kids who are going on about how it sounds like their favourite band, then invade your space in terms of Facebook, then I suspect you probably will have problems'. This respondent drew attention to the way fans may be able to comment and harass bands, making judgements about their sources and originality of the their music. At the same time that 
copying is mediated and monitored through the ethics of musicians and fans, it also confronts a further set of values associated with the business, commerce and copyright as we shall now discuss.

\section{The ownership of originality and the conflicts of commerce and copyright}

The creation of new popular music is premised upon two seemingly incompatible aesthetic beliefs. First, musicians wish to create music that acknowledges peers, that relates to a recognisable repertoire; to communicate identity by signalling a tradition to which the musician and audience belong; an orientation shaped by imitating. Second, musicians are motivated by an imperative to be original, to be existentially authentic; to conform to beliefs about professional pride, creative integrity, sincerity and artistic responsibility.

Publishers, promoters and producers require familiar products that conform to existing formats, with known markets and audiences. Companies across the music industries, from record labels to advertising agencies and game sound designers, are all focused on the familiar when signing and recruiting songwriters and when commissioning music due to a resemblance to existing, successful models. Writing back in the 1940s Theodor Adorno and Max Horkheimer highlighted a comparable paradox when they wrote of a culture industry driven by a 'constant pressure to produce new effects (which must conform to the old pattern)' (Adorno \& Horkheimer, 1979 [1944]: 128), with Adorno making the same point when drawing evidence from the study of music publishers: 'The publisher wants a piece of music that is fundamentally the same as all the current hits and simultaneously fundamentally different from them. ... this double desideratum cannot be fulfilled' (2002 [1941]: 448)

Although Adorno highlighted a contradiction at the heart of the commercial music production, his writings have frequently been dismissed due to their attention to apparently out-dated or irrelevant music when compared with the repertoire valued in the popular music studies canon. Even sympathetic critics, such as Richard Middleton (1990), acknowledge that Adorno's criticism have a historical value but argue that he failed to identify musical exceptions to his arguments about sameness and pseudo-individuality, cases that might offer alternative possibilities. Yet, for Adorno, the exceptions (writing with Horkheimer he acknowledges the films of Orson Welles) simply confirm the crushing pressure to conform rather than offering new possibilities. 
Yet, Bernard Gendron has suggested that Adorno's account of production is indeed plausible beyond his time and applies equally to 'the Sex Pistols as it does to Guy Lombardo and the Andrews Sisters' (1986: 25). Gendron takes issue with the way Adorno ignored how audiences 'take as much pleasure in the recognition of sameness as they do in the discovery of minute differences' (25), and cautions against making a leap from commercial industrial structures to political and aesthetic judgments.

If audiences find pleasures in sameness, as Gendron suggests, then so too do musicians. Copying in the varied ways we have discussed - is an illustration of the pleasures of the familiar. Rather than view this as alienating, as a distraction from impulses for social change, we might view this as an indication of the human desire for empathy, understanding and communication. Adorno values the new over the familiar, but our research suggests a profound value to the familiar.

Musicians, as we have shown, are acutely aware of how these pleasures and desires - for similarity and difference - become tensions when creative practice confronts commercial imperatives, compounded when filtered through copyright law with its requirement of 'original' intellectual 'properties' with identifiable 'owners'.

'Originality' was used in English since the fourteenth century, but became more widely applied only from the eighteenth century (Williams, 1983). During this time the term shifted from a static sense of origin to original as 'an authentic work of art' (Williams, 1983: 230); from a sense of the first work (origin) to a notion of 'new' with originality in the sense of unlike other works (not involving imitation) becoming 'a common term of praise of art and literature' (p230). Just as critics and scholars came to adjudicate on the criteria that make an artwork 'original', so too the legal establishment came to mediate how copyright law arbitrates in the judicial protection of originality.

Copyright law does not define originality but merely values it as the act of originating something, regardless of any other aesthetic characteristics or criteria. As a consequence, judges and courts must inevitably abandon this narrow definition when evaluating claims about copying and originality. Typically, the notion of 'originality' that is articulated in court cases draws upon Romanticism or a narrowly understood labour theory of value (Barron, 2006; Lutticken, 2002). As 
Jane Gaines has observed 'the strict legal definition of "original work" [is] nothing more than a work produced by an originator. But it may then abruptly lapse into value judgements that betray preference for elite culture's dismissal of anything that is "imitative" or genuinely "original".' (1991: 12).

In everyday practice, the tensions highlighted in this essay remain submerged or latent. Copying becomes an issue when commercial success and financial reward are involved; when the consequences of copying can potentially impact upon revenues and reputations (which in turn affect employability and earning potential). Amateur and unknown musicians (Finnegan, 2007 [1989]) and those at the 'margins' of the music industry (Phillips \& Street, 2015) tend to create music with little concern for the legal consequences of any copying. This point came over strongly when musicians reflected on the moment when they had to consider how they might get around or comply with copyright law. A songwriter who had achieved commercial success with a number of songs said:

When I know a song is going get a lot more airplay, or there'll be a lot more people listening, I do become more aware ... So I suppose I have thought about it, since songs have been played on the radio, you just have to a be bit more, just extra careful I guess.

When accusations of plagiarism are concluded via out of court settlement, or when judges make decisive rulings about what constitutes originality and copying, it is usually publishers, agents, lawyers and professional experts that are engaged in the arguments and the resulting decisions about recompense and allocation of resources. Rarely do musicians get involved in the discussion, unless called as witnesses. An experienced manager of bands and musicians made this very point when observing that disputes are usually between companies. He suggested that musicians may have a more profound and philosophically nuanced understanding of copying. When referring to a specific case he observed:

These disputes about authorship are effectively being carried out by people that are not the authors, which I find intriguing. What would have been a far more interesting, at least on a conceptual level, would have been to have, if the guy that wrote the song was still alive, and the band to sit down and to talk about it. Not as a basis of negotiation, but it would be really interesting, because my suspicion would be that on neither side would money be the primary 
concern. ... I think you would find that the people who have been sampled, whilst obviously enjoying the financial rewards of it will also get a great deal of - I'm not saying that this was in any way the case in this example - but in certain instances the kind of cultural recognition or cultural capital that you get out of being incorporated into somebody's work 40 years on, or 30 years on, must be some form of validation, surely.

This brings us back to a point made at the beginning of this article and re-connects copying in circulation with copying in the creative process. Many musicians allow their recordings to be circulated without payment because it encourages awareness and ultimately may lead to recognition. As a consequence, recordings being circulated have impact and influence on other musicians, signalled in the way that the recorded song is referenced, used as a model, quoted or sampled, or subject to homage in tributes or online uploads. The following quote is typical of a musician thinking about the importance of communication and recognition, and how becoming part of a tradition is as important as the incentive to make money:

I'm not gonna make money out of they sales of the CDs, right, because I really can't expect that. Then just purely for at least.. ego... it's nice to see that someone threw the whole album up on YouTube and lots of people are saying 'Ah man, I used to go see these guys back in the day' and all that kind of stuff. It's quite nice. So, honestly, if nothing else I can say, 'Hey look', I can prove it. I can show it to someone who would have trouble believing. ... And all these people who still like it. So, on that side of it, this sort of mass availability means you're not completely forgotten.

Here, allowing copying in circulation becomes a way for musicians to acknowledge other musicians. It is a riposte to the rhetorical metaphor of 'piracy' that collapses all nuances of circulation to an economic transaction and an equally narrow understanding of (copy)rights.

\section{The values of copying}

In this article we have illustrated the varied ways that copying is central to the creation and circulation of popular music. First, we have stressed the importance of the recording as an inspirational source of knowledge, learning and skill acquisition. The digital recording may no longer have economic exchange value for an industry, nor symbolic value for consumers who skip 
into and out of tracks on their mobile phones. But, the recording endures as a means by which musicians learn, pass on knowledge and communicate their art and signal their belonging to traditions and styles.

Second, our study of musicians suggests a value to imitation. An engagement with the known and familiar illustrates how copying allows important forms of empathy, understanding and belonging. Our point in highlighting this is to suggest that we should be critical of believing that the same styles, genres and songs structures are simply the result of a commercial imperative and we should also be sceptical of perspectives (dominant in modernist discourse) which unproblematically claims a value for the new without interrogating the importance of the familiar. Future research should perhaps explore in more depth the aesthetic and political possibilities of familiarity, and how this might be part of a much longer story about collective or common patterns of human creativity (see Boyle, 2008)

Third, we should be sceptical of any argument for the value of originality that does not acknowledge how musicians achieve originality through copying (however originality might be defined, debated or contested). In this essay we have outlined three types of copying that are integral to popular music creativity, practices that carry legacies from a long and diverse history and which cross genres and social identities. Copying as imitation to acquire skills, knowledge and understanding can lead to copying as a means of breathing new life and attributes into preexisting models and revived forms, and can also lead to a decision to imitate for commercial gain.

Finally, the musicians we spoke with highlighted how audiences are increasingly conscious of inspiration and imitation, aware of how bands and musicians knowingly draw on existing sources, and are sceptical of claims to originality, are aware of inter-textuality, copying and influence. This is apparent in discussions on various forums and platforms through which digital music is circulated. Yet, at the very same time, audiences and musicians also maintain an ethics of originality, often using social media (such as Facebook, Twitter or YouTube) to expose and to provoke debate about exploitation (speaking of plagiarism and 'rip offs'). Far too often arguments about plagiarism are reduced to the apparently objective claims about melodic and harmonic similarity, rather than the more intersubjective debates about responsibility and respect as these mediate the creative moments from copy to original. 


\section{Bibliography}

Adorno, Theodor (2002 [1941] 'On Popular Music' in Richard Leppert (ed) Essays on Music.

Berkley, CA: University of California Press.

Adorno, Theodor and Horkheimer, Max (1979 [1944]) Dialectic of Enlightenment. London: Verso.

Alderman, John (2002) Sonic Boom: Napster, Mp3, and the New Pioneers of Music, New York: Basic Books.

Aguiar, Luis \& Martens, Bertin (2013) Digital Music Consumption on the Internet: Evidence from Clickstream Data, Sevilla, Spain: Joint Research Centre of the European Commission.

Arewa, Olufunimilayo, (2011) 'Creativity, Improvisation and Risk: Copyright and Musical Innovation' Notre Dame Law Review 86 (5): 1829-1846.

Barron, Anne (2006) 'Copyright Law's Musical Work', Social \& Legal Studies, 15(1), 101-127

Behr, Adam, Brennan, Matt, \& Cloonan, Martin (2016) 'Cultural value and cultural policy: some evidence from the world of live music', International Journal of Cultural Policy, 22:3, 403-418

Benkler, Yochai (2006) The Wealth of Networks, How Social Production Transforms Markets and Freedom, New Haven, CT: Yale University Press.

Bennett, Andy (2006) 'Even better than the real thing? Understanding the tribute band phenomenon' in Shane Holman (ed) Access All Eras: Tribute Bands and Global Pop Culture, Maidenhead: Open University Press, 19-31.

Boyle, James (2008) The Public Domain: Enclosing the Commons of the Mind, New Haven, CT: Yale University Press.

Brocken, M. 2003. The British Folk Revival, 1944-2002, Farnham: Ashgate 
Brøvig-Hanssen, Ragnhild \& Harkins, Paul (2012). Contextual incongruity and musical congruity: the aesthetics and humour of mash-ups. Popular Music, 31:1, pp 87-104

Brown, Howard Mayer (1982) 'Emulation, Competition, and Homage: Imitation and Theories of Imitation in the Renaissance' Journal of the American Musicological Society, 35 (1): 1-48.

Burke, Peter (1997) The Renaissance, Second Edition London: Palgrave MacMillan.

Burrows, Donald (2012) Handel, Second Edition, Oxford: Oxford University Press.

Cross, Brian (1994) It's Not About a Salary: Rap, Race and Resistance in Los Angeles, London: Verso.

Cummings, Alex (2013) Democracy of Sound: Music Piracy and the Remaking of American Copyright in the Twentieth Century, Oxford: Oxford University Press.

David, Matthew (2010) Peer to Peer and the Music Industry: The Criminalisation of Sharing, London: Sage.

Finnegan, Ruth (2007 [1989]) The Hidden Musicians, Music-Making in an English Town, Second Edition, Middletown, CT: Wesleyan University Press.

Forde, Eamonn (2012) 'How Free is Ruining Everything', Q Magazine 17 July 2012, http://www.qthemusic.com/470/column-free-ruining-everything/ - accessed 12 April 2013.

Gaines, Jane (1991) Contested Culture: The Image, The Voice and The Law. Chapel Hill, NC: University of North Carolina Press.

Gendron, Bernard (1986) 'Theodor Adorno Meets the Cadillacs' in Tania Modleski (ed) Studies in Entertainment: Critical Approaches to Mass Culture. Bloomington: Indiana University Press, 18-36. 
Green, Lucy (2002) How Popular Musicians Learn, Farnham: Ashgate.

Green, Lucy (2008) Music, Informal Learning and the School: A New Classroom Pedagogy, Farnham: Ashgate.

Hardy, Phil (2012) Download, How the Internet Transformed the Record Business, London: Omnibus Press.

Hosokawa, Shuhei (2002) ‘Blacking Japanese: Experiencing Otherness From Afar’ in David Hesmondhalgh \& Keith Negus (eds) Popular Music Studies. London: Arnold, 223-237.

Johns, Adrian (2010) Piracy: The Intellectual Property Wars from Gutenberg to Gates, Chicago: University of Chicago Press.

IFPI (2011) Digital Music Report 2011, London: IFPI (International Federation of the Phonographic Industry).

IFPI (2012) Digital Music Report 2012, London: IFPI (International Federation of the Phonographic Industry).

IFPI (2013) Digital Music Report 2013, London: IFPI (International Federation of the Phonographic Industry).

IFPI (2014) Digital Music Report 2014, London: IFPI (International Federation of the Phonographic Industry).

Knopper, Steve (2009) Appetite for Self Destruction: The Spectacular Crash of the Record Industry in the Digital Age, New York: Simon \& Schuster.

Lessig, Lawrence (2005) Free Culture: The Nature and Future of Creativity, London: Penguin. 
Lessig, Lawrence (2008) Remix: Making Art and Commerce Thrive in the Hybrid Economy, London: Bloomsbury.

Leyshon, Andrew (2014) Reformatted: Code, Network and the Transformation of the Music Industry, Oxford: Oxford University Press.

Lloyd, Albert L (1967). Folk Song in England, London: Lawrence \& Wishart.

Lutticken, Sven (2002) 'The Art of Theft', New Left Review, 13, Jan-Feb, 89-104.

Marshall, Lee (2002) 'Metallica and Morality: The Rhetorical Battleground of the Napster Wars', Entertainment Law, 1(1), 1-19

Marshall, Lee (2015) 'Let's Keep Music Special. F- Spotify': On-demand streaming and the controversy over artist royalties' Creative Industries Journal, 8 (2): 177-189.

McLeod, Kembrew \& Kuenzul, Rodolf (eds.) (2011), Cutting Across Media: Appropriation Art, Interventionist Collage, and Copyright Law, Durham and London: Duke University Press

McLeod, Kembrew and DiCola, Peter (2011) Creative License: The Law and Culture of Digital Sampling Durham and London: Duke University Press

Middleton, Richard (1990) Studying Popular Music, Milton Keynes: Open University Press.

Milne, Richard (2014) 'The Spotify Effect' Financial Times Magazine, 24/25 October, online version http://www.ft.com/cms/s/0/59e6e6d6-5a49-11e4-8771-00144feab7de.html - accessed 22 October 2014.

Morris, Jeremy \& Powers, Devon (2015) 'Control, curation and musical experience in streaming services' Creative Industries Journal, 8 (2): 106-122. 
Negus, Keith (2015) 'Digital divisions and the changing cultures of the music industries (or, the ironies of the artefact and invisibility)', Journal of Business Anthropology, 4(1), 151-157

Phliips, Tom \& Street, John (2015) 'Copyright and Musicians at the Digital Margins' Media, Culture \& Society, 37 (3): 342-358.

Reynolds, Simon (2013) Retromania, Pop Culture's Addiction to Its Own Past, London: Faber and Faber.

Rogers, Jim (2013) The Death and Life of the Music Industry in the Digital Age, London:

Bloomsbury.

Rosen, Ronald (2008) Music and Copyright Oxford: Oxford University Press.

Seabrook, John 'Revenue Streams' The New Yorker, 24 November 2014, http://www.newyorker.com/magazine/2014/11/24/revenue-streams - accessed 5 January 2015.

Shiga, John (2007) 'Copy-and-persist: the logic of mash-up culture', Critical Studies in Media Communication, 24:2, pp. 93-114

Williams, Raymond (1983) Keywords, A Vocabulary of Culture and Society, London: Fontana.

Williams, Raymond (1963) Culture and Society, London: Pelican.

Zollo, Paul (2003) Songwriters on Songwriting, Fourth Edition, New York: da capo. 
${ }^{1}$ This work was supported by the RCUK funded Centre for Copyright and New Business Models in the Creative Economy (CREATe) [AHRC Grant Number AH/K000179/1]. 